\title{
Descriptions of the female, male and mature larva of Simulium contractum Takaoka (Diptera: Simuliidae) from Sulawesi, Indonesia
}

\author{
Takaoka, H. ${ }^{*}$, Sofian-Azirun, M. ${ }^{2}$, Chen, C.D. ${ }^{2}$, Halim, M.R.A. ${ }^{2}$, Lau, K.W. ${ }^{2}$, Low, V.L. ${ }^{1}$ and \\ Wayan Suana, I. ${ }^{3}$ \\ ${ }^{1}$ Tropical Infectious Diseases Research and Education Centre (TIDREC), University of Malaya, Kuala Lumpur, \\ 50603 Malaysia \\ ${ }^{2}$ Institute of Biological Sciences, Faculty of Science, University of Malaya, Kuala Lumpur, 50603 Malaysia \\ ${ }^{3}$ Faculty of Mathematics and Natural Science, University of Mataram (UNRAM), Mataram, 83125 Indonesia \\ *Corresponding author e-mail: takaoka@oita-u.ac.jp \\ Received 1 May 2020; received in revised form 3 June 2020; accepted 3 June 2020
}

\begin{abstract}
Simulium (Simulium) contractum Takaoka from Sulawesi, Indonesia was known only as the pupa. Its female, male and mature larva are described for the first time. The tentative assignment of this species in the Simulium dumogaense species-group is confirmed by the adult characters including the female and male genitalia. The female and male of this species are similar to those of Simulium (Simulium) tumpaense Takaoka \& Roberts but are distinguished by the yellowish femora.
\end{abstract}

\section{INTRODUCTION}

The fauna of black flies (Diptera: Simuliidae) has been well studied in Sulawesi, where all of the 47 species recorded are classified in the genus Simulium Latreille and are further placed in four subgenera: 22 species in Gomphostilbia Enderlein, three species in Nevermannia Enderlein, 21 species in Simulium Latreille s. str., and one species in Wallacellum Takaoka (Adler, 2019; Takaoka et al., 2019).

Most of species of the subgenus Simulium in Sulawesi are placed in two species-groups, nine in the $S$. dumogaense species-group and 11 species in the $S$. variegatum species-group (Takaoka, 2017), wheras one species, S. parvulum Takaoka, remained in an unplaced group due to lack of adult and pupal stages (Takaoka, 2017; Adler, 2019).

In 2019, we conducted surveys in several streams in Maros, southern Sulawesi, Indonesia and collected pupae and mature larvae of $S$. contractum Takaoka and obtained female and male adults reared from the pupae. This species was described only based on a pupal exuviae and cocoon (Takaoka, 2003), and was placed in the $S$. dumogaense species-group, defined by Takaoka (2017). This species is, though known only as the pupa, distinguished from other members of the same species-group by the pupal gill filaments, of which three or four filaments each has a maximal width at some distance from the base (Takoaka, 2003).

We describe the female, male and mature larva of $S$. contractum and confirm the placement of this species in the $S$. dumogaense species-group by adult characters including female and male genitalia. All specimens examined are deposited in Faculty of Mathematics and Natural Science, University of Mataram (UNRAM), Mataram, 83125 Indonesia.

The methods of collection, description and illustrations, and terms for morphological features used here, follow those of Takaoka 
(2003) and partially those of Adler et al. (2004).

\section{Simulium (Simulium) contractum Takaoka, 2003}

Simulium (Simulium) contractum Takaoka, 2003: 539-541 (Pupa).

Female (n=5). Body length 2.0-2.1 mm. Head. Narrower than width of thorax. Frons brownish-black, shiny and iridescent when illuminated at certain angles, with several fine dark and dull hairs along lateral margins and near lower margin; frontal ratio 1.31.4:1.0:1.1-1.4; frons:head ratio 1.0:3.7-3.8. Fronto-ocular area triangular, directed laterally and slightly upwardly. Clypeus brownish-black, shiny and iridescent when illuminated at certain angles, whitish pruinose, moderately covered with fine dark and dull hairs except small areas near upper margin bare. Labrum 0.55-0.60 times length of clypeus. Antenna composed of scape, pedicel and nine flagellomeres, medium brown except scape, pedicel and base of first flagellomere yellow. Maxillary palp light brown, composed of five palpomeres, proportional lengths of third, fourth, and fifth palpomeres 1.0:1.2:2.1-2.2; third palpomere (Fig. 1A) normal; sensory vesicle (Fig. 1A) small, ellipsoidal, $0.25-0.27$ times length of third palpomere, with mediumsized round opening medially. Maxillary lacinia with 8-12 inner and 12 outer teeth. Mandible with 24 or 25 inner and 10-12 outer teeth. Cibarium (Fig. 1B) with 8-12 minute pointed processes and about dozen of round nodules. Thorax. Scutum brownish black, shiny, thinly whitish pruinose when illuminated at certain angles, moderately covered with fine whitish yellow recumbent short hairs. Scutellum brownish black, with dark-brown stout upright hairs. Postnotum dark brown, shiny, whitish pruinose when illuminated at certain angles and bare. Pleural membrane bare. Katepisternum longer than deep, dark brown, bare, shiny and iridescent when illuminated at certain angles. Legs. Foreleg: coxa and trochanter yellowish white; femur yellow with apical cap light brown; tibia whitish except apical cap brownish black, subbasal portion light to medium brown (except on outer surface) and medial portion dark yellow to light brown on inner surface; tarsus blackish; basitarsus moderately delated, 5.0-5.3 times as long as its greatest width. Mid leg: coxa dark brown except posterolateral surface brownish black; trochanter yellowish white; femur yellow except apical cap slightly darkened; tibia yellow though most of outer surface light to medium brown ; tarsus dark brown except basal five-sixths of basitarsus yellowish white. Hind leg: coxa medium brown; trochanter yellowish white; femur yellow except apical cap light brown; tibia medium to dark brown except base yellowish white; tarsus brownish black except little more than basal two-thirds of basitarsus and basal half of second tarsomere yellowish white; basitarsus (Fig. 1C) nearly parallel-sided, 5.6-5.8 times as long as its greatest width, $0.7-0.8$ and 0.6 times as wide as greatest widths of hind tibia and femur, respectively; calcipala nearly as long as width at base, and 0.4 times as wide as greatest width of basitarsus; pedisulcus distinct; claw without basal tooth. Wing. Length 1.6-1.7 mm. Costa with dark brown spinules and light brown hairs. Subcosta haired except apical onethird bare. Basal section of vein $R$ bare; $R_{1}$ with dark brown spinules and dark hairs; $R_{2}$ with dark hairs only. Hairs at base of radial vein light brown. Basal cell absent. Halter. White except base darkened. Abdomen. Basal scale dark brown, with fringe of yellow long hairs. Dorsal surface of abdominal segments dark brown to brownish-black, with dark hairs; tergite 2 with pair of large whitish iridescent dorsolateral spots broadly connected to each other medially; tergites 5-9 shiny. Ventral surface of abdominal segment 7 with pair of sternal plates. Terminalia. Sternite 8 (Fig. 1D) well sclerotized, and moderately covered with numerous short to long hairs on each side. Ovipositor valve (Fig. 1D, E) triangular, well sclerotized (fused with posterior portion of sternite 8) except narrow portion along inner margin and near apex thin, transparent and membranous, and covered with numerous short to medium-long hairs on ventral surface; inner margins well sclerotized, nearly straight or slightly sinuous, widely 
separated from each other. Genital fork (Fig. 1F) of inverted-Y form; stem slender, well sclerotized; arms slender, each with strongly-sclerotized angulate lateral ridge having triangular projection directed anteriorly. Paraproct in ventral view (Fig. 1G) with dark, elliptical, wide, moderatelysclerotized anteroventral plate having about 30 dark hairs scattered on its surface, though several hairs closely clustered and much stouter and longer than other setae; paraproct in lateral view (Fig. $1 \mathrm{H}$ ) much produced ventrally, 0.8 times as long as its width, covered with numerous short to medium-long hairs on lateral surface, and with dark moderately-sclerotized anteroventral plate having cluster of stout hairs on its surface. Cercus in lateral view (Fig. 1H) short, rounded posteriorly, 0.5 times as long as its greatest width, and covered with several short to medium-long hairs. Spermatheca (Fig. 1I) nearly globular, well sclerotized except duct and wide area of juncture with duct unsclerotized, without reticulate surface patterns; minute internal setae present; both accessory ducts subequal in diameter to each other, and also to that of main duct.

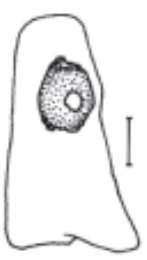

A

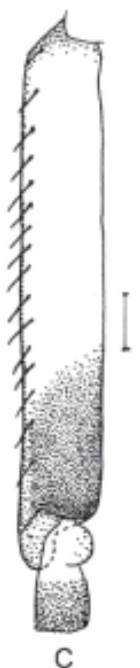

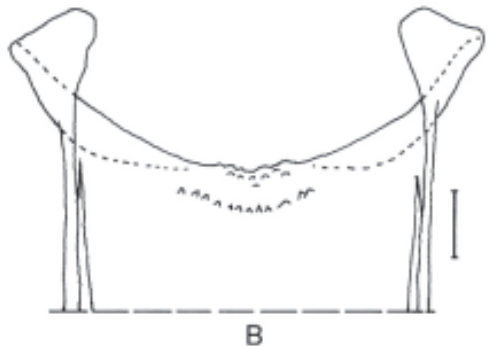

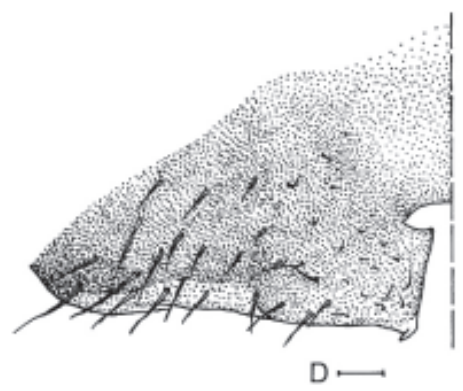

$\mathrm{D} \longrightarrow$
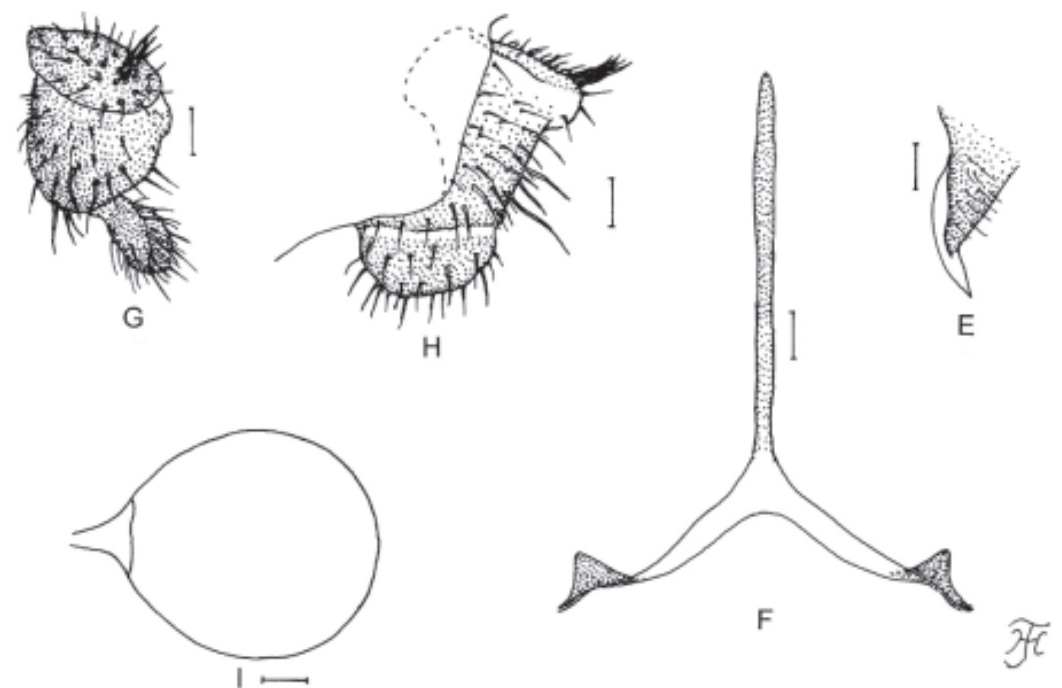

Figure 1. Female of Simulium contractum. (A) Third palpomere of maxillary palp with sensory vesicle (right side; front view). (B) Cibarium. (C) Basitarsus and second tarsomere of hind leg (left side; outer view). (D) Sternite 8 and ovipositor valve (ventral view; right side only). (E) Ovipositor valve (left side; medial view). (F) Genital fork (ventral view). (G) \& (H) Paraprocts and cerci (right side; G, ventral view; $\mathrm{H}$, lateral view). (I) Spermatheca. Scale bars. $0.05 \mathrm{~mm}$ for C; $0.02 \mathrm{~mm}$ for A, B and D-I. 
Male (n=7). Body length 2.0-2.3 mm. Head. Somewhat wider than thorax. Upper eye consisting of large facets in 14 or 15 vertical columns and 15 (rarely 14 or 16) horizontal rows on each side. Clypeus brownish-black, whitish-pruinose, shiny and iridescent when illuminated at certain angles, moderately covered with dark-brown long hairs. Antenna composed of scape, pedicel and nine flagellomeres, light to medium brown; first flagellomere somewhat elongate, 1.3-1.5 times length of second. Maxillary palp light brown, composed of five palpomeres, proportional lengths of third, fourth, and fifth palpomeres 1.0:1.3:2.2; third palpomere (Fig. 2A) of normal size; sensory vesicle small, globular or ellipsoidal, 0.18 times length of third palpomere, and with small opening. Thorax. Scutum brownish-black, with different color pattern formed by whitishgray pruinose and non-pruinose portions: at certain angle of light, scutum widely whitish gray pruinose except inverted T-shaped median portion non-pruinose (Fig. 2B), and at certain other angle of light, scutum widely whitish gray pruinose except pair of lateral spots and narrow mediolongitudinal line nonpruinose (Fig. 2C) (though mediolongitudinal non-pruinose line absent in some males); scutum densely covered with yellowishwhite fine recumbent fine short hairs intermixed with dark similar fine hairs near anterior margin and interspersed with darkbrown long upright hairs on prescutellar area. Other characters similar to those of female.

Legs. Color pattern almost similar to that of female. Fore tarsus with thick dorsal crest of short hairs; basitarsus nearly parallel-sided, 5.6-6.1 times as long as its greatest width. Hind basitarsus (Fig. 2D) nearly parallelsided, 5.4-5.6 times as long as its greatest width, $0.6-0.7$ and 0.6 times as wide as greatest widths of hind tibia and femur, respectively; calcipala nearly as long as its basal width, and 0.4 times as wide as greatest width of basitarsus; pedisulcus distinct. Wing. Length 1.5-1.6 mm; other characters as in female except subcosta entirely bare. Halter. White except base darkened. Abdomen. Basal scale dark brown, with fringe of pale long hairs (though darkened basally). Dorsal surface of abdomen dark brown to brownish-black, with dark hairs; segments 2 and 4-7 each with pair of silvery iridescent dorsolateral spots, broadly connected in middle on segment 2 but not on other segments; tergites of segments 8 and 9 shiny laterally. Genitalia. Coxites, styles and ventral plate in ventral view are as in Fig. 2E. Coxite in ventral view (Fig. 2E) nearly quadrate. Style in ventrolateral view (Fig. 2F) elongate, 1.5 times length of coxite, 2.2 times as long as its greatest width, widened from base to basal one-third, then narrowed slightly toward round apex, and with stout subapical spine; style in medial view (Fig. 2G) flattened dorsoventrally, and with short basal protuberance, which is triangular when viewed posteriorly. Ventral plate in ventral view (Fig. 2E) with body nearly rectangular having ventrallyproduced median process covered with minute setae; basal arms short, stout and divergent; ventral plate in lateral view (Fig. 2I) with body and its ventrally-produced process with rounded ventral apex, and covered with minute setae; ventral plate in caudal view (Fig. 2J) with body and ventrallyproduced median process nearly triangular, covered with minute setae. Median sclerite in lateral view (Fig. 2I) weakly sclerotized, folded backward and then curved dorsally, and in caudal view (Fig. 2K) plate-like and wide. Paramere (Fig. 2L) wide basally and with several parameral hooks apically. Aedeagal membrane (Fig. 2M) densely covered with minute setae, with weakly sclerotized dorsal plate (Fig. 2N). Ventral surface of tenth abdominal segment without any distinct hairs. Cercus small and rounded, with 4-11 distinct hairs.

Mature larva $(\mathrm{n}=3)$. Body length 4.5-5.0 $\mathrm{mm}$. Body whitish with following color markings: thoracic segment 1 encircled with grayish brown band; thoracic segments 2 and 3 light grayish dorsally and grayish brown ventrally; abdominal segments 1-4 each with grayish brown transverse band dorsally and dorsolaterally, though disconnected dorsomedially; abdominal segments 1-3 grayish ventrally; abdominal segments 5-8 grayish brown dorsally and dorsolaterally; abdominal segments 1-6 with 


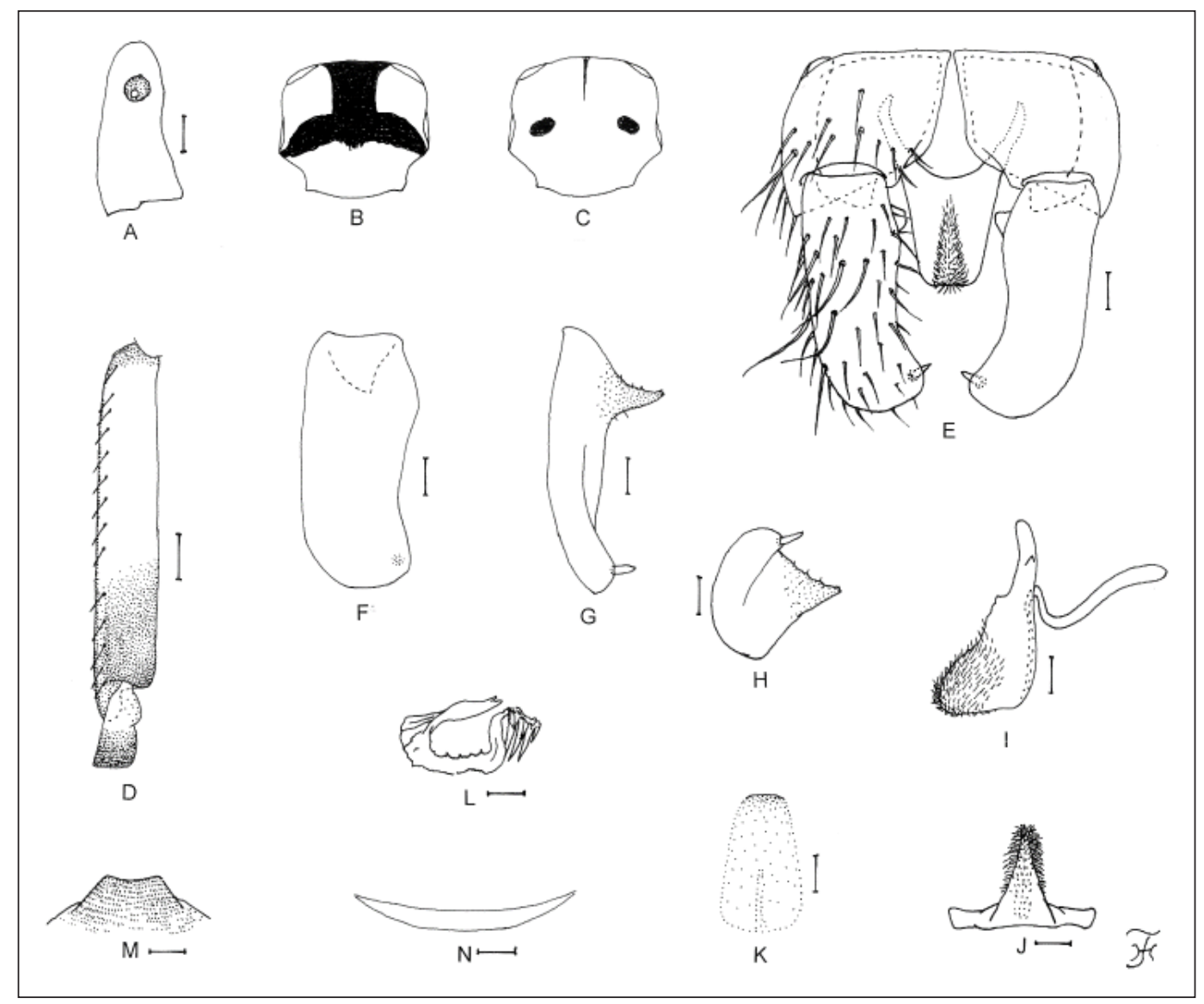

Figure 2. Male of Simulium contractum. (A) Third palpomere of maxillary palp with sensory vesicle (right side; front view). (B) \& (C) Scuta showing different color patterns (dorsal view). (D) Basitarsus and second tarsomere of hind leg (left side; outer view). (E) Coxites, styles and ventral plate (ventral view). (F), (G) \& (H) Styles (right side; F, ventrolateral view; G, medial view; $H$, caudal view; $G$ \& $H$ showing basal protuberance). (I) Ventral plate and median sclerite (lateral view). (J) Ventral plate (caudal view). (K) Median sclerite (caudal view). (L) Paramere (right side; caudal view). (M) Aedeagal membrane (caudal view). (N ) Dorsal plate (ventral view). Scale bars. $0.05 \mathrm{~mm}$ for D; $0.02 \mathrm{~mm}$ for A and E-N.

narrow grayish brown mediolangitudinal line; abdominal segment 7 with wine-red short line connected with anterior grayish line, and two wine-red submedial spots ventrally; abdominal segment with wine-red spot laterally on each side; all grayish brown portions overlaid with wine-red pigments to varying extent. Abdomen subequal in width from segment 1 to segment 4, then somewhat widened to segment 6 , and narrowed to segment 9. Cephalic apotome whitish except narrow area along posterior margin slightly darkened, with indistinct head spots except mediolateral spots somewhat darkened in one larvae; cephalic apotome whitish except area between posterolateral head sopts and posterior margin along posterior margin medium-brown to brownish black and lateral area between mediolateral head spots and posterolateral spots light brown; head spots light brown except anterior one of mediolongitudinal spots indistinct; mediolateral and posterolateral spots merged with dark surrounding areas (Fig. 3A) in two larvae; lateral and ventral surface of head capsule entirely whitish or yellowish white and ventral and lateral spots indistinct in one larva, but wide area along posterior margin including two large lateral spots dark brown and elongate spot on each side of postgenal 
cleft light brown (Fig. 3B) in two other larvae. Antenna composed of three articles and apical sensillum, slightly longer than stem of labral fan; proportional lengths of first, second, and third articles 1.0:1.0:0.6-0.7. Labral fan with 38-40 primary rays. Mandible (Fig. 3C) with mandibular serrations composed of two teeth; major and longer tooth at obtuse angle to mandible on apical side; comb-teeth decreasing in length from first to third. Hypostoma (Fig. 3D) with nine anterior teeth, median and corner teeth most prominent; lateral margins not serrate apically; five or six hypostomal bristles lying divergent posteriorly from lateral border on each side. Postgenal cleft (Fig. 3B) large, rounded, deep, 3.7-5.0 times length of postgenal bridge. Cervical sclerites composed of pair of dark small rod-like pieces. Pharate pupal gill with six filaments, of which three or four filaments with their maximum width at some distance from base. Thoracic cuticle almost bare. Abdominal cuticle almost bare except each side of anal sclerite moderately covered with short colorless setae, and lateral bulges of last segment sparsely covered with fine colorless setae. Rectal scales present. Rectal organ of compound lobes, each with six finger-like secondary lobules. Anal sclerite X-shaped, with broadened anterior arms 0.6 times length of posterior ones; one or two sensilla on basal juncture area; four to six sensilla posterior to posterior armas. Last abdominal segment bulged laterally but lacking ventral papillae. Posterior circlet with 88-94 rows of hooklets with up to 15 hooklets per row.

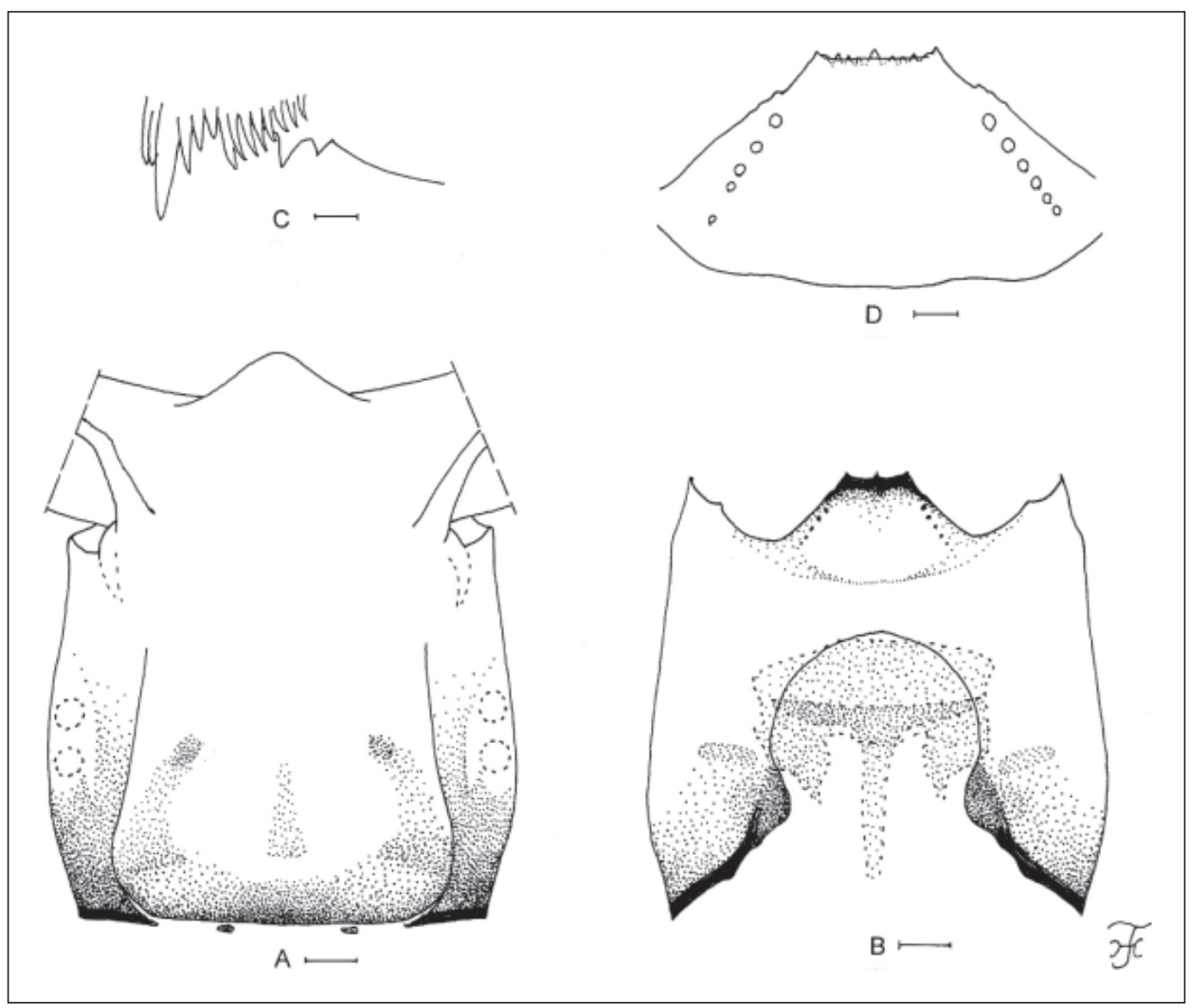

Figure 3. Larva of Simulium contractum. (A) \&(B) Head capsules (A, dorsal view; B, ventral view). (C) Mandible. (D) Hypostoma. Scale bars. $0.05 \mathrm{~mm}$ for A and B; $0.02 \mathrm{~mm}$ for D; $0.01 \mathrm{~mm}$ for $\mathrm{C}$. 
Specimens examined. Five females, seven males (all reared from pupae and preserved together with their pupal exuviae and cocoons) (in 80\% ethanol), and three mature larvae (in 80\% ethanol), collected from a moderately-flowing stream (width $3-5 \mathrm{~m}$, depth 15-20 cm, bottom rocky and sandy, $30.0^{\circ} \mathrm{C}$, partially shaded, elevation $54 \mathrm{~m}$, $\left.4^{\circ} 58^{\prime} 44.886 " \mathrm{~S}, 119^{\circ} 40^{\prime} 25.898^{\prime \prime} \mathrm{E}\right)$, Leang Leang, Bantimurung, Maros, southern Sulawesi, Indonesia, 4-IV-2019, by M. SofianAzirun, C.D. Chen, M.R.A. Halim, K.W. Lau \& I.W. Suana.

Biological notes. The pupae and larvae of this new species were collected from plastic sheets and grass leaves in the water. Associated species were $S$. (Gomphostilbia) marosense Takaoka, Sofian-Azirun \& Suana and S. (Simulium) tumpaense Takaoka \& Roberts.

Remarks. Simulium contractum was placed in the $S$. dumogaense species-group based on the pupal characters such as the gill with six filaments, abdominal segments 5 and 6 each ventrally lacking an outer hook on each side, and cocoon shoe-shaped, resembling those of $S$. tumpaense known as a member of the $S$. dumogaense speciesgroup from Sulawesi (Takaoka, 2017). The previous assignment of this species to the $S$. dumogaense species-group is here confirmed by the female and male key characters including the paraproct having an anteroventral plate with stout setae (Fig. $1 \mathrm{G}, \mathrm{H}$ ), and style having an basal protuberance (Fig. 2G, H).

The adults of this species are similar to those of $S$. tumpaense described from Sulawesi (Takaoka \& Roberts, 1988) in many characters including the female claw without tooth, short triangular ovipositor valve (Fig. 1D), number of male upper-eye (large) facets, and ventral plate without distinct teeth on the posterior surface (Fig. 2J). However, this species is distinguished from $S$. tumpaense in both the female and male by the femora widely yellow except the apical cap darkened (mostly medium to dark brown in $S$. tumpaense), and in the male by the hind basitarsus almost parallel-sided and 5.4-5.6 times as long as its greatest width (gradually widened toward the apex and 3.8-4.3 times as long as its greatest width in S. tumpaense), and basal protuberance triangular, tapered toward the apex (Fig. 2G) (with a widely rounded apex when viewed medially in $S$. tumpaense).

The pupae of this species reexamined in this study show that the dorsum of abdominal segments 1 and 2 is light to medium brown (entirely on abdominal segment 1, and rarely and limited to a narrow portion along the anterior margin of abdominal segment 2) and is covered with minute tubercles; and the dorsum of abdominal segment 9 also is light brown and has transverse rows of comb-like groups of micro- spines. The color and the presence or absence of minute tubercles on the pupal abdomen were insufficiently described in the original description (Takaoka, 2003), although they are important pupal characters in species identification.

The larvae of this species are almost indistinguishable from those of $S$. tumpaense except the pharate pupal gill with six somewhat inflated filaments, of which three or four filaments have their maximum width at some distance from the base (all filaments with maximal width basally in $S$. tumpaense).

Acknowledgement. This work was supported by the research grant from Universiti Malaya (RP021A/16SUS and BR006/2016).

\section{REFERENCES}

Adler, P.H. (2019). World Blackflies (Diptera: Simuliidae): A Comprehensive Revision of the Taxonomic and Geographical Inventory [2019]. 139 pp., http://entweb. clemson.edu/biomia/pdfs/blackfly inventory.pdf [accessed on May. 30, 2019] Adler, P. H., Currie, D.C. \& Wood, D.M. (2004). The Black Flies (Simuliidae) of North America. xv+941 pp., Cornell University Press, Ithaca, New York, USA.

Takaoka, H. (2003). The Black Flies (Diptera: Simuliidae) of Sulawesi, Maluku and Irian Jaya. xxii+581 pp., Kyushu University Press, Fukuoka, Japan. 
Takaoka, H. (2017). Morphotaxonomic revision of species-groups of Simulium (Simulium) (Diptera: Simuliidae) in the Oriental Region. Zootaxa 4353(3): 425446.

Takaoka, H. \& Roberts, D.M. (1988). Notes on blackflies (Diptera: Simuliidae) from Sulawesi, Indonesia. Japanese Journal of Tropical Medicine and Hygiene 16(3): 191-219.
Takaoka, H., Sofian-Azirun, M., Chen, C.D., Halim, M.R.A., Lau, K.W., Low, V.L. \& Suana, I.W. (2019). A new black fly species of Simulium (Gomphostilbia) (Diptera: Simuliidae) from Sulawesi, Indonesia. Zootaxa 4651(2): 392-400. 